\title{
Amended agriculture appropriation bill would eliminate Class-B dealers
}

On 20 September 2005, the United States Senate agreed by voice vote to accept Senator Daniel K. Akaka's (D-HI) amendment to the 2006 agriculture funding bill (Agriculture, Rural Development, food and Drug Administration, and Related Agencies Appropriations Act, 2006, H.R. 2744 (ref. 1)) to "prohibit Federal funding of research facilities that purchase animals from Class-B dealers ${ }^{2,3}$."

Class-B animal dealers supply random source animals to research facilities. They obtain these animals from pounds, shelters, dog owners who wish to surrender their ownership, and other legitimate sources, and, in keeping with United States Department of Agriculture (USDA) animal welfare regulations, must keep identification records linking each random source animal to its original owner. Because the public is concerned that Class$B$ dealers may deal in stolen animals, the USDA audits research facility and dealer records in order to ensure that the dogs and cats that these dealers sell originate from legitimate sources ${ }^{4}$.

Several organizations, including the National Association for Biomedical Research ${ }^{5}$, the American Physiological Society $^{6}$, the the Society of Toxicology ${ }^{7}$, have released statements objecting to the intended and unintended consequences of this amendment, and have petitioned the Senate to reconsider it. They believe that Class-B dealers are already well regulated and do not steal animals for research, that eliminating Class-B dealers would deprive researchers and teachers of larger, older, and more genetically diverse animals than those that Class-A dealers (those licensed dealers who breed their animals) may be able to provide, and that research facilities would have to pay higher costs for their animals. Research facilities receiving funds from the USDA or United States Food and Drug Administration (FDA) would lose them should they obtain animals from Class-B dealers.

1. H.R. 2744. Agriculture, Rural Development, Food and Drug Administration, and Related Agencies Appropriations Act, 2006 (Engrossed Amendment as Agreed to by Senate).

2. S.AMDT.1729 to H.R. 2744 To prohibit Federal funding of research facilities that purchase animals from Class-B dealers. Sponsor: Senator Daniel K. Akaka. Introduced 15 September 2005. Senate amendment agreed to. Status: Amendment SA 1729 agreed to in Senate by Voice Vote on 20 September 2005.

3. H.R. 2744. Bill Summary \& Status for the 109th Congress. Resolving differences/ConferenceSenate actions. Status: Senate insists on its amendment, asks for a conference, appoints conferees. (22 September 2005).

4. USDA APHIS. Animal Care: A New Era in Animal Welfare. (February 2002).

5. National Association for Biomedical Research. NABR Talking Points: Opposition to Akaka Amendment to HR 2744.

6. American Physiological Society. Public Affairs Alert. Animal Research in Jeopardy. (29 September 2005).

7. Society of Toxicology. USDA and FDA Appropriations Alert.

\section{Compromise struck on European chemical testing legislation}

On 4 October 2005, the European Union (EU) Parliament's Environment Committee agreed, by a vote of 40-19, to support changes to REACH (Registration, Evaluation and Authorisation of Chemicals) legislation that would reduce testing and reporting requirements for low-volume chemical manufacturers ${ }^{1}$.

Originally proposed in October 2003 and currently being debated in the EU Parliament, REACH would overhaul the EU's chemical regulatory system, requiring manufacturers to register chemicals and provide safety testing information. REACH is intended to "increase the protection of human health and the environment from exposure to chemicals while at the same time to maintain and enhance the competitiveness and innovative capabilities of the EU chemicals industry ${ }^{2}$."

In a concession to industry groups that have expressed concern that the implementation of REACH would be detrimental to small businesses, the Environment Committee agreed to ease requirements on testing and reporting for substances produced in quantities of $1-10$ tons $^{1}$. Approximately 17,500 chemicals fall into this category ${ }^{3}$.

To keep animal testing to a minimum, another approved amendment to the bill would require that in vitro tests, where available, be used instead of animal tests. In addition, companies would be required to consult with the European Centre for the
Validation of Alternative Methods (ECVAM) before using animals in any tests, and to contact the European Chemicals Agency-the new agency that will manage the data-with the results of all animal tests ${ }^{1}$.

This report will be forwarded to the full assembly, which is scheduled to vote on it on 15 November. The final piece of legislation will take effect in 2007.

1. European Parliament Press Service. Chemicals directive: a difficult balance to strike. (5 0ctober 2005).

2. European Commission publishes new draft Chemicals Legislation for consultation. (7 May 2003).

3. EurActiv.com. REACH-committee under fire. (4 October 2005). 